\title{
Complementary Feeding and the Nutritional Status of Children 6-23 Months Attending Kahawa West Public Health Center,Nairobi
}

\author{
Angelica Kimwele ${ }^{1}$, Sophie Ochola ${ }^{2}$ \\ ${ }^{1}$ (Department of Human Nutrition and Dietetics, Technical University of Kenya, P.O.Box 52428-00200 Nairobi \\ Kenya) \\ ${ }^{2}$ (Department of Food Nutrition and Dietetics, Kenyatta University P.O.Box 43844 -00100 Nairobi- Kenya)
}

\begin{abstract}
A cross-sectional analytical study was carried out at the Kahawa West Public Health Centre, Nairobi, Kenya, among randomly sampled 286 mothers and their children aged 6-23 months. Data was entered and analyzed using (SPSS version 20). Anthropometric measurements were analyzed using ENA for SMART. Chi-square test $(p<0.05)$ was used to show the relationships. The respondents were mostly young (mean age $26.1 \pm 4.7$ years), married (88.1\%), housewives (66.4\%) with mainly primary school level of education $(47.2 \%)$. The main sources of income for most households were business (48.6\%) and casual labour (31.8\%). All (100\%) the children aged 6-8 had been introduced to solids, semi-solids and soft foods. Majority of the breast-fed children received minimum meal frequency; 6-8 months old (95.9\%) and 9-23 months old (96.4\%) unlike the non-breast fed children (55.0\%). The percentage of children who consumed vitamin A rich foods was $60.8 \%$ and iron-rich foods were $11.5 \%$. Over three quarters (79.0\%) of the children attained the minimum dietary diversity whereas $75.9 \%$ attained the minimum acceptable diet. Overall, $13.3 \%$ of all the children were stunted, $11.9 \%$ wasted and $16.8 \%$ underweight. Children who did not attain the minimum meal frequency were likely to be wasted (chi-square test; 0.001) and underweight (chi-square test; 0.013).Nutrition messages on Infant and Young Child Feeding Practices should emphasis dietary diversity and frequency of feeding especially for nonbreastfed children.
\end{abstract}

Keywords: complementary feeding, minimum acceptable diet, minimum meal frequency, minimum dietary diversity.

\section{Introduction}

World Health Organization (WHO) recommends exclusive breastfeeding for the first 6 months, introduction of complementary feeding with continued breastfeeding for at least 2 years [1]. The recommended infant and young child feeding practices for children aged 6-23 months include: continued breastfeeding; feeding semi-solid/solid food according to the age of the child; and feeding a variety of foods such as cereals, fruits, vegetables [2].Breastfeeding of up to 2 years of age and beyond is an important source of nutrients, fluids and immunological protection, while appropriate complementary food promotes good health, nutritional status and growth of young children [1]. In many developing countries, complementary feeding is introduced too early and the quality and quantity of the foods are insufficient, thus children are at the risk of nutritional deficiency [3]. Most of the complementary foods are cereal-based gruels low in energy and nutrient density and more so inadequate in iron, zinc, pyridoxine, riboflavin, niacin, calcium, thiamine, foliate, ascorbic acid and vitamin A [4].

Malnutrition has been responsible directly or indirectly for $60 \%$ of the 10.9 million deaths annually among children under 5 years in the whole world, where two thirds of these deaths are associated with inappropriate feeding practices in the first year of life [5]. In developing countries, malnutrition accounts for $50 \%$ deaths of the children under five years [6]. In Africa, malnutrition contributes to half of the 9.7 million annual under five deaths and is a leading cause of diseases and disabilities in children [7, 8]. In Kenya, inappropriate complementary feeding practices contribute to more than 10000 annual deaths for children under five years [9]. Malnutrition rates for the under fives in 2008 were, 7\% wasted, 35\% stunted and 16\% underweight based on the Kenya Demographic [10]

In Kenya, complementary foods are introduced as early as the first month and by 6 months $84 \%$ of the infants are already receiving complementary feeds, where some of these foods are low in energy and micronutrients [9]. Only 39\% of the Kenyan children aged 6-23 months are fed in accordance with the WHO recommended IYCF guidelines [10]. This coupled with unhygienic preparation and storage conditions predisposes many infants to diarrhoea and inadequate diet causing a negative impact on growth and development, which is very characteristic in this age group [9]. The general nutritional status of children under five years for the period 2000 to 2008-09 shows that since 2003, the proportion of stunted children has remained 
unchanged, in fact stunting levels in the age group 6-11 has increased from $15.3 \%$ to $21.6 \%$. In Nairobi province, stunting rates have increased by 4 points $(18.7-22.7 \%)$, underweight children although lowest in Nairobi province has since almost doubled $6.3 \%$ to $10 \%$ [10]. So, this study presumed that it is worthy to conduct a study to assess mother's complementary feeding for evidence based programme planning and intervention. It is also envisaged to provide information about existing complementary feeding practices of the mothers so that the appropriate steps could be taken to fulfill the goals of the appropriate complementary feeding practices.

\subsection{Study design and subjects}

\section{Methods}

A cross-sectional analytical design was used in this study. The study was carried out in Kahawa West Public Health Centre, which is 25 kilometers from the Nairobi City center in an easterly direction along Thika and Kamiti road. Only mothers of children aged 6-23 months, attending Kahawa West Public Health Centre and willing to participate were included in the study. The sample size was calculated using Yamane (1967) Formula for an estimated population of 1000 mothers and respective children and The Yamane (1967:886) .A final sample size of 286 mothers and their respective children was used for this study. Mothers and their children aged 6-23 months were selected at the Child Welfare Clinic

\subsection{Study instrument}

A structured questionnaire was administered to the sampled mothers and their children aged 6-23 months attending Kahawa West Public Health Centre. It included information on; socio-economic and demographic characteristics, complementary feeding practices and child's anthropometric measurements. A the focus group discussion guide was developed based on maternal perception on complementary feeding. It verified mother's complementary feeding and solicited their views on IYCN practices.

Weight was measured in kilograms at 10 grams accuracy where a UNICEF Salter Scale Model $2356 \mathrm{~S}$ was used. Since this study was carried out in a child welfare clinic, all the children had child health cards from where the children's age was recorded. The length of the child was measured in centimeters using a pediatric height board of standard design (SECA) with 0.1 Centimeter accuracy. The questionnaire was pre-tested on 10 mothers and their respective children aged 6-23 months old attending Kasarani public Health Centre before the study. The structured questionnaire was then rephrased in the light of the responses. Kasarani Public Health Centre neighbours Kahawa West Public Health Centre. Content validity was established in the structured questionnaire using the indicators for the assessment of Infant and Young Child Feeding Practices [11] and the guiding principles for complementary feeding for a breastfed child [12]. The questionnaire was presented to experts in nutrition from Kenyatta University in the department of Food, Nutrition and Dietetics to establish content validity.Test-retest reliability of the research instrument was established during pretesting there liability co-efficient was 0.89 and therefore the questionnaire was considered reliable.

\subsection{Analysis}

Socio-economic and demographic characteristics, maternal knowledge and practices on complementary feeding were analyzed using Statistical Package for Social Sciences (S PSS version 20). The child nutritional status was analyzed using ENA for SMART and interpreted using the Z- Score [1]. Children with a Z-score of below -2SD for WFA, WFH and HFA were considered underweight, wasted and stunted respectively. Children below -3SD for WFA, WFH and HFA were considered severely malnourished. Children between -2SD and 3SD for the above indices were considered moderately malnourished. Those above -2SD were considered normal or well nourished [1].

Complementary feeding practices indicators: Minimum dietary diversity, minimum meal frequency, minimum acceptable diet, and introduction of solids, semi-solids and soft foods. Minimum dietary diversity was based on a child having consumed foods from four or more of the food groups; grains/roots/tubers, dairy products, flesh foods (meat, fish, poultry), egg, vitamin A rich vegetables and others fruits or vegetables. Minimum meal frequency was adequate it was 2 times for breastfed infants 6-8 months, 3times for breasted infants 9-23 months and 4 times for non-breastfed children of 6-23 months. Introduction of solid, semi-solids and soft foods at 6-8 months and minimum acceptable diet was attained if a child had the minimum meal frequency and minimum dietary diversity [8].Chi-square test $(\mathrm{p}<0.05)$ was used to investigate the relationship between mothers' complementary feeding practice and child nutritional, logistic regression analysis was used to determine the strength of association. Data from focus group discussions was triangulated with the data from the questionnaire. 


\section{Results}

3.1Demographic and socio-economic characteristics of the mothers and children

Both sexes were almost equally represented with $49.3 \%$ being males and $50.7 \%$ females (Table 1 ). The majority of the children were in the age range of 6-12 months (75.2\%) with an average age of $10.56 \pm 3.96$ months. The youngest mother was 17 years while the oldest was 48 years with the mean age for all mothers being $26.1 \pm 4.7$ years. Many $(88.1 \%)$ of the mothers were married with the rest $(11.8 \%)$ being either single or separated. On the whole, mothers had low level of education; over one percent $(1.7 \%)$ had never gone to school while only $0.7 \%$ had reached the university; a notable proportion had primary school level of education $(47.2 \%)$, secondary school level of education $(35.3 \%)$ and vocational training $(15 \%)$. The mothers' economic status was low as more than half $(66.4 \%)$ of them were housewives, $22.4 \%$ were engaged in petty trade and domestic workers, only $9.8 \%$ were in waged labour while $1.3 \%$ were unemployed and students (Table, 1 ).

Table 1: Demographic characteristics of the children

\begin{tabular}{|l|l|l|}
\hline \multicolumn{2}{|c|}{ Children's demographic characteristics } & \multicolumn{2}{|c|}{ N=286 } \\
\cline { 2 - 3 } Sex of the child & n & \\
Male & 141 & 49.3 \\
Age of the children( months) & 145 & 50.7 \\
6-12months & 215 & 75.2 \\
13-23months & 71 & 24.8 \\
Mean (SD) Age $\quad \mathbf{1 0 . 5 6} \pm \mathbf{3 . 9 6}$ & & \\
Maternal age (years) & 25 & 8.6 \\
17-20 & 210 & 64.9 \\
21-30 & 51 & 26.5 \\
31-48 & & \\
Mean age (SD) & & \\
Marital status: & 252 & 88.1 \\
Married & 31 & 10.8 \\
Single & 3 & 1.0 \\
Separated & & \\
No education & 5 & 1.7 \\
Primary School & 135 & 47.2 \\
Secondary School & 101 & 35.3 \\
Vocational, College & 43 & 15 \\
University Degree & 2 & 0.7 \\
main occupation & & \\
Waged labour & 28 & 9.8 \\
Pretty trade/ domestic help & 64 & 22.4 \\
Unemployed/student & 4 & 1.3 \\
Housewife & 190 & 66.4 \\
\hline
\end{tabular}

\subsection{Socio-economic profiles of the households}

The major source of income for most households was businesses (48.6\%), followed by causal work (31.8\%), salaried employment (15.3\%), support by their parents $(2.1 \%)$, farmers $(1.7 \%)$ or relied on financial savings $(1.0 \%)$ and charity organizations $(1.4 \%)$.

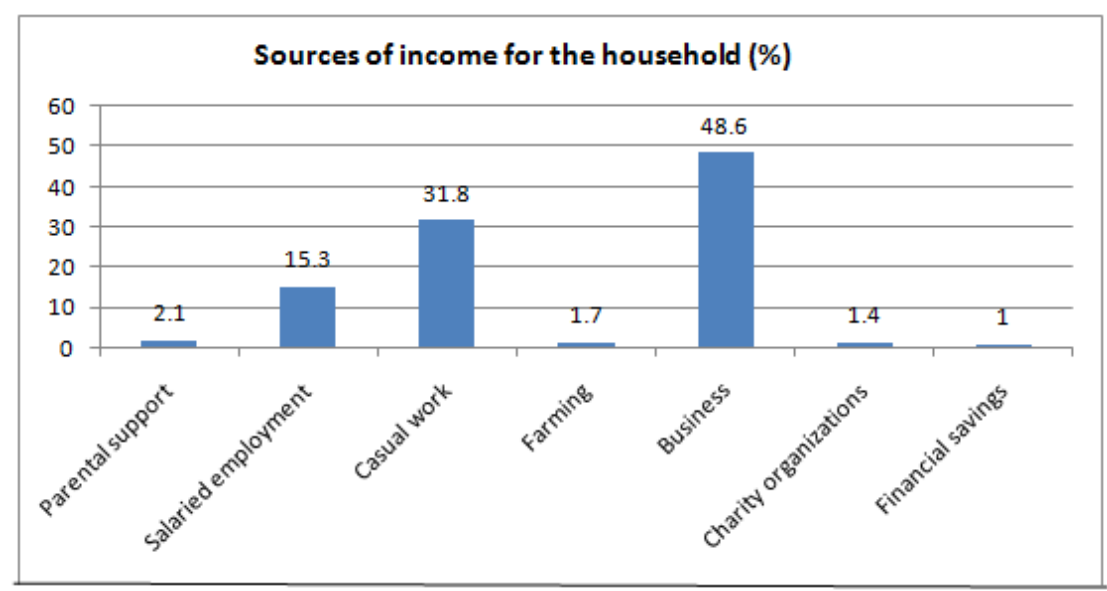

Figure,1: socio-economic profiles of the households 


\subsection{Household income and expenditure}

The mean monthly income for the households was Kenya Shillings (Kshs) 19,454 $\pm 12,580$. In terms of expenditure, the mean monthly rent was Kshs $2538 \pm 738$, education expenses Kshs $663 \pm 1231$, health Kshs $223 \pm 536$, and expenditure on airtime, clothing, leisure, investments and assistance to other relative was Kshs $1779 \pm 1440$. The respondents reported to be spending on average, a daily amount of Kshs $262 \pm 95$ on food for the whole household (Table 3.2).

Table 2: Household expenditure

\begin{tabular}{|l|l|l|}
\hline Household expenditure & \multicolumn{2}{|c|}{$\mathrm{N}=286$} \\
\cline { 2 - 3 } & Mean expenditure (Kshs) & $\begin{array}{l}\text { Standard } \\
\text { (SD) }\end{array}$ \\
\hline Average monthly income & 19,454 & $\pm 12,580$ \\
Monthly expenditure on rent & 2538 & $\pm 1,738$ \\
Daily expenditure on food & 262 & \pm 94 \\
Monthly expenditure on education & 663 & \pm 1230 \\
Monthly expenditure on health & 221.82 & \pm 535 \\
$\begin{array}{l}\text { Monthly expenses on airtime, clothing, leisure, } \\
\text { investments and support to other relatives }\end{array}$ & 1779.37 & \pm 1440 \\
\hline
\end{tabular}

\subsection{Breastfeeding practices}

Since complementary feeding is a period during which other foods or liquid are provided along with breast milk as defined by World Health Organization [13], breastfeeding was considered important. Almost all (99\%) of the children in the study had been breast fed but at the time of the study it had declined to $93 \%$ (Table $3.2)$.

Table 3: Breastfeeding practices

\begin{tabular}{|l|l|l|}
\hline \multirow{2}{*}{ Breastfeeding practices } & \multicolumn{2}{|c|}{ N=286 } \\
\cline { 2 - 3 } & N & \% \\
\hline Ever breastfed & 283 & 99 \\
Still breastfeeding & 266 & 93 \\
\hline
\end{tabular}

\subsection{Complementary feeding practices}

\subsubsection{Introduction of solids, semi-solids and soft foods}

The proportion of breastfed infants 6-8 months of age who receive solid, semi-solid or soft foods indicate timely introduction of complementary feeding [11]. Based on a 24-hour recall, $100 \%$ of the children, 68 months old had received solid or semi-solid foods although $21.6 \%$ had been complemented earlier (before 6 months), while a few of the children $(0.3 \%)$ had not started feeding by 9 months (Figure 2 ).

Figure 2: introduction to complementary feeding

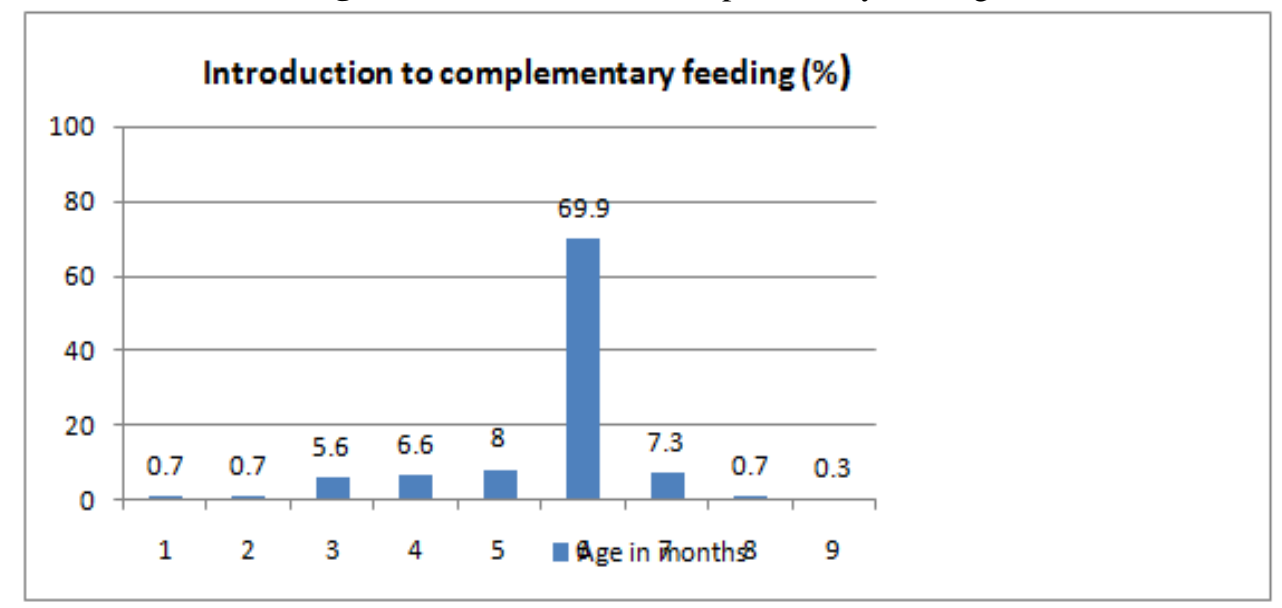




\subsubsection{Minimum meal frequency}

The WHO indicator for this variable was based on the breastfeeding status of the child of children 6-23 months of age. Breastfed infants $6-8$ months old should receive solid, semi-solid, or soft foods 2 times per day inclusive of snacks. Whereas those who are not breastfed should receive these foods 3 times per day inclusive of snacks. Breastfed children 9-23 months old should eat semi-solid and or soft foods 3 times per day and those who are non-breastfed 4 times per day inclusive of snacks for non-breastfed children 6-23 months [11]. Majority of the breastfed children 6-8 months old and 9-23 months old had attained the recommended minimum meal frequency of 2 times and 3 times per day at $95.9 \%$ and $96.4 \%$ respectively. Among the nonbreastfed children 6-23 months old, those who had attained the minimum meal frequency were 55\% (Table 3)

Table 3: Minimum meal frequency

\begin{tabular}{|l|l|l|}
\hline \multirow{2}{*}{ Age in months } & \multicolumn{2}{|c|}{$\mathbf{N = 2 8 6}$} \\
\cline { 2 - 3 } & Frequency of feeding & $\mathbf{n}(\mathbf{\%})$ \\
\hline Breastfed children (N=266) & & \\
6-8months ( $=98)$ & $\geq 2$ times & \\
& $<2$ times & $94(95.9)$ \\
9-23 months (n=168) & $\geq 3$ times & $4(4.1)$ \\
& $<3$ times & $162(96.4)$ \\
Non breast-fed children $(\mathbf{n}=\mathbf{2 0})$ & & $6(3.6)$ \\
6-23months(n=20) & & \\
& $\geq 4$ times & $11(55.0)$ \\
\hline
\end{tabular}

\subsubsection{Minimum dietary diversity}

The consumption of a varied diet suggests a possibility of a child to having taken a balanced diet which is an important aspect in the child's nutritional status. Minimum dietary diversity was established based on the number of food groups the index child consumed in the previous 24 hours prior to the data collection. Seven food groups as recommended internationally by WHO [11] were considered in the study. The food groups were: grains, roots and tubers; legumes and nuts; dairy products; meat and animal products; eggs; vitamin A rich fruits and vegetables and other fruits and vegetables. Majority of the children (95.5\%) had eaten food prepared from grains, tubers and roots. The intakes of vitamin A rich fruits and vegetables were $60.8 \%$, iron rich foods intakes (flesh meats) was $11.5 \%$ while the consumption of other fruits was relatively higher (71.4\%). Consumption of proteins was highest from dairy products (83.2\%), and lower in legumes (28\%) and least for flesh meats and eggs (11.5\%) and (2.4\%) respectively (Figure 3 ).

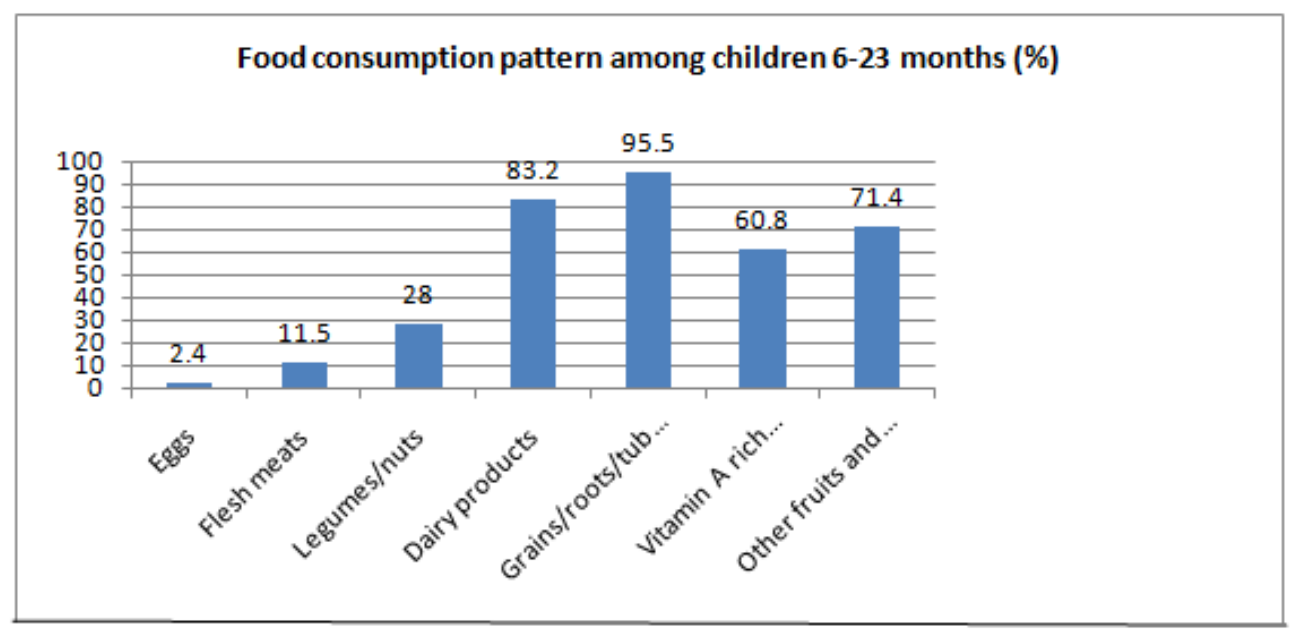

Figure 3: Food consumption among children 6-23 months

Children of 6-23 months of age both breastfed and nonbreastfed who receive foods from 4 or more food groups are considered to have a diverse diet [11].. Hence a minimum dietary diversity score was determined where more than three quarters $(79.0 \%)$ of the children had received food from the four food groups and above with a mean dietary intakes of 3.66 (1.03) (Table 3.4). 
Table 4: Dietary diversity score for complementary feeding

\begin{tabular}{|l|l|l|}
\hline \multirow{2}{*}{$\begin{array}{l}\text { dietary diversity score } \\
\text { (children 6-23 months) }\end{array}$} & \multicolumn{2}{|c|}{ N=286 } \\
\cline { 2 - 3 } & \multicolumn{1}{|c|}{ n } \\
\hline Children 6-23 months & 60 & \\
$<4$ food groups & 226 & 21.0 \\
$\geq 4$ food groups & $\mathbf{3 . 6 6} \pm \mathbf{1 . 0 3}$ & 79.0 \\
Mean dietary diversity score(sd) & & \\
& & \\
Children 6-11 months & 43 & 22.9 \\
$<4$ food groups & 145 & 77.1 \\
$\geq 4$ food groups & & \\
Children 12-17 months & 12 & 15.6 \\
$<4$ food groups & 65 & 84.4 \\
$\geq 4$ food groups & & \\
Children 18-23 months & 5 & 23.5 \\
$<4$ food groups & 16 & 76.2 \\
$\geq 4$ food groups & & \\
\hline
\end{tabular}

\subsubsection{Minimum acceptable diet}

These are the children 6-23 months who receive minimum meal frequency and minimum dietary diversity (WHO, 2007). Three quarters $(75.9 \%)$ of all the children had achieved minimum acceptable diet. Those children aged 6-11 months (75.5\%), 12-18 months (79.2\%) and 18-23 months (66.7\%) had achieved minimum acceptable diet. (Table, 5).

Table 5: Minimum acceptable diet

\begin{tabular}{|l|l|l|}
\hline Minimum acceptable diet & \multicolumn{2}{|c|}{ N=286 } \\
\cline { 2 - 3 } & $\mathbf{N}$ & \% \\
\hline Children 6-23 months(n=286) & 217 & 75.9 \\
Achieved & 6 & 24.1 \\
Not achieved & & \\
& & 75.5 \\
Children 6-11months (n=188) & 142 & 24.5 \\
Achieved & 46 & \\
Not achieved & & \\
Children 12-17 months(n=77) & 61 & 79.2 \\
Achieved & 16 & 20.8 \\
Not achieved & & \\
Children 18-23 months(n=21) & 14 & 66.7 \\
Achieved & 7 & 33.3 \\
Not achieved & & \\
\hline
\end{tabular}

\subsubsection{Maternal complementary feeding practices from the focus group discussions}

Mothers cited cultural beliefs and household economic status as the major challenges in adequate complementary feeding practices especially in provision of balanced meals. Mothers suggested the following to improve on complementary feeding practices; provision of food aid to the households, income generating activities for women and adequate knowledge on the correct child porridge flours (Table 6).

Table 6: Main findings on maternal knowledge and complementary feeding practices from the focus group discussions

\begin{tabular}{|l|l|l|}
\hline MGDs & $\begin{array}{l}\text { Main and common findings on maternal knowledge and perceptions on } \\
\text { complementary feeding practices }\end{array}$ \\
\hline Timely introduction of CF & $\bullet \quad$ Mothers knew the correct time to introduce complementary foods. \\
\hline Dietary diversity & $\begin{array}{l}\text { Mothers knew the contents of a balanced diet, but were not able to put this } \\
\text { into practice because of economic challenges. Cultural beliefs also } \\
\text { constrained the provision of balanced meals because some foods were } \\
\text { considered to be taboo for children for example eggs. Some of the food } \\
\text { combinations were: }\end{array}$ \\
\hline Feeding frequency & $\begin{array}{l}\text { Ugali (stiff porridge) accompanied with sour milk, boiled rice mixed with } \\
\text { Irish potatoes, boiled green bananas, while vegetables and fruits (pawpaw, } \\
\text { oranges, watermelon) milk and meats products in rare cases }\end{array}$ \\
\hline $\begin{array}{l}\text { Factor influencing complementary } \\
\text { feeding practices }\end{array}$ & $\begin{array}{l}\text { Based on child hunger cues, mothers' time availability and food } \\
\text { availability. }\end{array}$ \\
\hline
\end{tabular}




\begin{tabular}{|c|c|}
\hline & advice from the health workers \\
\hline $\begin{array}{l}\text { Mothers cultural beliefs on } \\
\text { complementary foods }\end{array}$ & 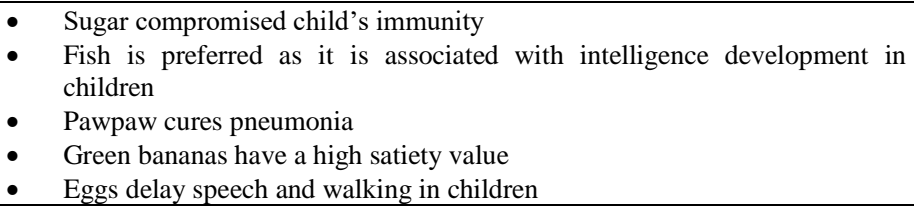 \\
\hline $\begin{array}{l}\text { Flours used for making porridge } \\
\text { flours }\end{array}$ & $\begin{array}{l}\text { - Mixtures of maize (unga baridi), beans, ndengu, millet sorghum, omena } \\
\text { (silver fish), and cassava. } \\
\text { These mixtures were readily available in the shops and therefore mothers } \\
\text { bought the flours from the shops by just mentioning the age of the child to } \\
\text { the shopkeeper. (give me porridge flour for a } 9 \text { month child-mother orders } \\
\text { from a shopkeeper) }\end{array}$ \\
\hline $\begin{array}{l}\text { Maternal opinion on the importance of } \\
\text { appropriate complementary feeding } \\
\text { practices }\end{array}$ & $\begin{array}{l}\text { - Children 6-23 months old who are not fed as required will lose weight, } \\
\text { have poor growth, become weak and sick }\end{array}$ \\
\hline $\begin{array}{l}\text { Challenges experienced by mothers in } \\
\text { complementary feeding }\end{array}$ & $\begin{array}{ll}- & \text { High food prices } \\
\text { - } & \text { Poverty/ inadequate money to buy food } \\
\end{array}$ \\
\hline $\begin{array}{l}\text { Mothers suggestions for optimal } \\
\text { IYCN practices }\end{array}$ & 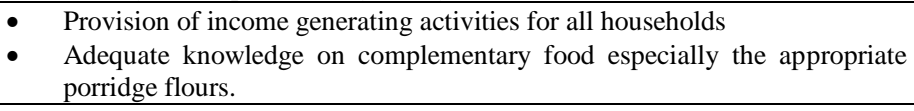 \\
\hline
\end{tabular}

\subsection{Nutritional status of the children}

\subsubsection{Stunting (height-for-age) based on $\mathrm{Z}$ scores}

In this study, $13.3 \%(9.8-17.795 \% \mathrm{CI})$ of all the children were stunted with more boys $18.4 \%$ (12.9 $25.695 \%$ C.I.) than girls $8.3 \%$ (4.8 - 13.9 95\% C.I.) stunted. About one-tenth 8.4\% (5.7-12.2 95\% C.I.) were moderately stunted, while $4.9 \%$ (2.9-8.0 95\% C.I.) were severely stunted (Table 7).

Table 7: Prevalence of stunting by sex based on Z-scores

\begin{tabular}{|c|c|c|c|}
\hline & $\begin{array}{l}\text { All } \\
\mathrm{n}=286\end{array}$ & $\begin{array}{l}\text { Boys } \\
n=141\end{array}$ & $\begin{array}{l}\text { Girls } \\
\mathrm{n}=145\end{array}$ \\
\hline $\begin{array}{l}\text { Stunting } \\
(<-2 \text { z-score })\end{array}$ & $\begin{array}{l}(38) 13.3 \% \\
(9.8-17.795 \% \text { C.I. })\end{array}$ & $\begin{array}{l}\text { (26) } 18.4 \% \\
(12.9-25.695 \% \text { C.I.) }\end{array}$ & $\begin{array}{l}\text { (12) } 8.3 \% \\
(4.8-13.995 \% \text { C.I.) }\end{array}$ \\
\hline $\begin{array}{l}\text { Moderate stunting } \\
(<-2 \mathrm{z}-\mathrm{score} \text { and }>=-3 \mathrm{z}- \\
\text { score })\end{array}$ & $\begin{array}{l}\text { (24) } 8.4 \% \\
(5.7-12.295 \% \text { C.I.) }\end{array}$ & $\begin{array}{l}\text { (16) } 11.3 \% \\
\text { (7.1 - } 17.695 \% \text { C.I.) }\end{array}$ & $\begin{array}{l}\text { (8) } 5.5 \% \\
(2.8-10.595 \% \text { C.I.) }\end{array}$ \\
\hline $\begin{array}{l}\text { Severe stunting } \\
\text { (<-3 z-score) }\end{array}$ & $\begin{array}{l}\text { (14) } 4.9 \% \\
(2.9-8.095 \% \text { C.I.) }\end{array}$ & $\begin{array}{l}\text { (10) } 7.1 \% \\
(3.9-12.695 \% \text { C.I.) }\end{array}$ & $\begin{array}{l}\text { (4) } 2.8 \% \\
(1.1-6.995 \% \text { C.I.) }\end{array}$ \\
\hline
\end{tabular}

\subsubsection{Wasting (weight-for-height) based on $Z$ scores}

The global wasting rate in this study was $11.9 \%$ (8.6-16.2 95\% C.I.) with more boys $17.0 \%$ (11.7-24.1 95\% C.I.) than girls $6.9 \%$ (3.8-12.2 95\% C.I.) wasted. One-tenth of the children 9.8\% (6.9-13.8 95\% C.I.), were moderately wasted and $2.1 \%$ (1.0-4.5 95\% C.I) were severely wasted (Table 8).

Table 8: Prevalence of acute malnutrition by sex- based on Z-scores and/or oedema

\begin{tabular}{|c|c|c|c|}
\hline & $\begin{array}{l}\text { All } \\
\mathrm{n}=286\end{array}$ & $\begin{array}{l}\text { Boys } \\
\mathrm{n}=141\end{array}$ & $\begin{array}{l}\text { Girls } \\
\mathrm{n}=145\end{array}$ \\
\hline $\begin{array}{l}\text { Global malnutrition } \\
(<-2 \text { z-score })\end{array}$ & $\begin{array}{l}\text { (34) } 11.9 \% \\
(8.6-16.295 \% \text { C.I. })\end{array}$ & $\begin{array}{l}\text { (24) } 17.0 \% \\
(11.7-24.195 \% \text { C.I. })\end{array}$ & $\begin{array}{l}\text { (10) } 6.9 \% \\
(3.8-12.295 \% \text { C.I. })\end{array}$ \\
\hline $\begin{array}{l}\text { Moderate malnutrition } \\
(<-2 \text { z-score and >=-3 z-score) }\end{array}$ & $\begin{array}{l}\text { (28) } 9.8 \% \\
(6.9-13.895 \% \text { C.I. })\end{array}$ & $\begin{array}{l}\text { (19) } 13.5 \% \\
(8.8-20.195 \% \text { C.I. })\end{array}$ & $\begin{array}{l}\text { (9) } 6.2 \% \\
\text { (3.3 - } 11.495 \% \text { C.I.) }\end{array}$ \\
\hline $\begin{array}{l}\text { Severe malnutrition } \\
(<-3 \text { z-score })\end{array}$ & $\begin{array}{l}\text { (6) } 2.1 \% \\
(1.0-4.595 \% \text { C.I. })\end{array}$ & $\begin{array}{l}\text { (5) } 3.5 \% \\
(1.5-8.095 \% \text { C.I. })\end{array}$ & $\begin{array}{l}\text { (1) } 0.7 \% \\
(0.1-3.895 \% \text { C.I. })\end{array}$ \\
\hline
\end{tabular}

\subsubsection{Underweight (weight-for-age) based on Z-scores}

In this study $16.8 \%$ (12.9-21.5 95\% C.I.) of the children were underweight, whereas almost double the percentages of boys $22.0 \%$ (15.9-29.5 95\% C.I.) than girls $11.7 \%$ (7.5-18.0 95\% C.I) were underweight. On the whole, $13.3 \%$ (9.8-17.7 95\% C.I.) of all the children were moderately underweight while 3.5\% (1.9-6.3 95\% C.I.) were severely underweight (Table, 9). 
Table 9: Prevalence of underweight based on weight-for-age Z-scores by sex

\begin{tabular}{|c|c|c|c|}
\hline & $\begin{array}{l}\text { All } \\
\mathrm{n}=286\end{array}$ & $\begin{array}{l}\text { Boys } \\
\mathrm{n}=141\end{array}$ & $\begin{array}{l}\text { Girls } \\
\mathrm{n}=145\end{array}$ \\
\hline $\begin{array}{l}\text { Underweight } \\
(<-2 \text { z-score })\end{array}$ & $\begin{array}{l}\text { (48) } 16.8 \% \\
(12.9-21.595 \% \text { C.I.) }\end{array}$ & $\begin{array}{l}\text { (31) } 22.0 \% \\
(15.9-29.595 \% \text { C.I. })\end{array}$ & $\begin{array}{l}\text { (17) } 11.7 \% \\
\text { (7.5 - } 18.095 \% \text { C.I.) }\end{array}$ \\
\hline $\begin{array}{l}\text { Moderately } \\
\text { underweight } \\
(<-2 \text { z-score and >=-3 } \\
\text { z-score })\end{array}$ & $\begin{array}{l}\text { (38) } 13.3 \% \\
(9.8-17.795 \% \text { C.I. })\end{array}$ & $\begin{array}{l}\text { (24) } 17.0 \% \\
(11.7-24.195 \% \text { C.I.) }\end{array}$ & $\begin{array}{l}\text { (14) } 9.7 \% \\
(5.8-15.695 \% \text { C.I. })\end{array}$ \\
\hline $\begin{array}{l}\text { Severe underweight } \\
\text { (<-3 z-score) }\end{array}$ & $\begin{array}{l}\text { (10) } 3.5 \% \\
(1.9-6.395 \% \text { C.I. })\end{array}$ & $\begin{array}{l}\text { (7) } 5.0 \% \\
(2.4-9.995 \% \text { C.I.) }\end{array}$ & $\begin{array}{l}\text { (3) } 2.1 \% \\
(0.7-5.995 \% \text { C.I. })\end{array}$ \\
\hline
\end{tabular}

\subsection{Relationship between mothers' complementary feeding practices and child nutritional status}

Relationships between child nutritional status (wasting, underweight and stunting) and complementary feeding practices in terms of minimum dietary diversity, minimum meal frequency and minimum acceptable diet, Timely introduction of complementary foods (consumption of solid, semi-solid and soft foods for children 6-8 months old) and its association with child nutritional status was not investigated since all (100\%) the children aged 6-8 months had consumed a solid, semi-solid and soft food.)

A chi-square test revealed a significant relationship between minimum meal frequency and both wasting and underweight $(\mathrm{p}=0.001$ and $\mathrm{p}=0.013$ ) respectively. Children who had consumed fewer meals in a day than recommended by WHO were more likely to be wasted and underweight than those who were fed the minimum meal frequency as WHO recommendations (Table, 3.10).

Table 10: The association between mothers' complementary feeding practices and child nutritional status

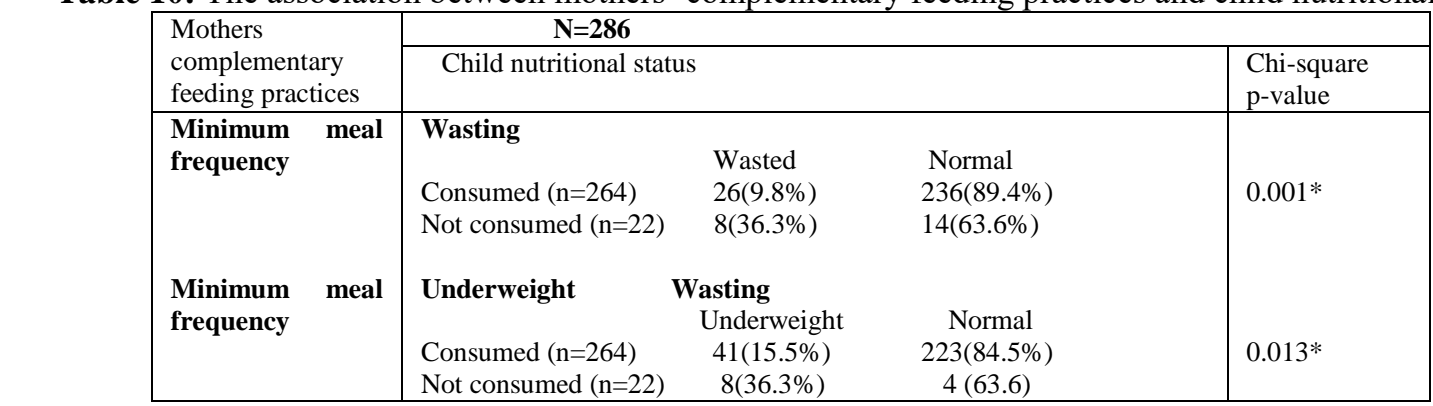

*Significant relationship at $\mathrm{p}$-value $<0.05$

\section{Discussions}

In this study, almost all the children had been breast fed and this compares with the Kenya national figures as reported in Kenya Demographic Health Survey [10], and in Kibera slum Nairobi (Fotso, Gitau, Kyobutangi, Malise, Mutua and Yatich, 2011) and in Korogocho slum Nairobi [15] This was also expected given that culturally Africans breastfeed their children. During complementary feeding, for infants and young children aged 6-23 months old, breastfeeding contributes significantly to the overall nutrient intake, fills most of the energy needs and remains an important source of vitamin A and C, as well as essential fatty acids and can provide to their total energy needs [16].

The mothers introduced complementary feeding foods to their children timely; all the children 6-8 months had been appropriately introduced to solids, semi-solid and soft foods. This finding compares to those of in Korogocho slum Nairobi [15], at the age of 6 months, an infant's need for energy and nutrients starts to exceed what is provided by breast milk, thus complementary foods are necessary to meet energy and nutrient requirements, [13], and if complementary foods are not introduced when a child has completed 6 months of age, an infant's growth may falter [17]. Dietary diversity has long been recognized as a key element of high quality diets and increasing the variety of foods consumed is thought to ensure adequate intake of essential nutrients and thus promote good health and nutrition [18]. Majority of the children had eaten food prepared from grains, tubers and roots like porridge, ugali, rice, chapatti, bread, potatoes, yams and cassavas. This is comparable to the Kenya national figures as reported in Kenya Demographic Health Survey KDHS [10] and findings of a study by Blomme, Garming and Ekesa [19], in Butembo-Democratic Republic of Congo.

This can be related to the fact that being a low income community, the mothers would go for the cheaper foods which are usually grains/roots/tubers and their products and the fact that cereals form the staple food of any community. Porridge was also taken by almost all the children in this study since this is a common complementary food. Other studies have also reported the same findings by a study in the rural western Kenya and a study conducted in Utter Pradesh[20,21]. 
The consumption of proteins was highest from dairy products mostly milk, concurring with the study findings by in Batudu District of Nepal [22] and in Gitega (Burundi) and Butembo (Democratic Republic of Congo) [19]. The lower consumptions of legumes and least for flesh meats and eggs could be as a result of financial constrains and cultural beliefs as mothers reported in the focus group discussion. Mothers reported that eggs are prohibited for children as they interfere with speech and walking (consumption of eggs will make child slow in walking and speech.). The majority of the households could not afford expensive food items like eggs and flesh meats which are rich in iron.

This sentiment was expressed by the mothers during the FGDs. The mean dietary diversity was below the recommended $\geq 4$ food groups [9], although higher than Kenya national figure as reported in Kenya Demographic Health Survey KDHS [10], (58.4\%) In the present study, mothers' knowledge on the importance of providing balanced diet for their child was adequate and probably their low socio-economic status may have affected their ability to give a diverse diet to the children. Additionally, in the FGDs, mothers reported that cultural beliefs influenced the type of foods given to children; for example some of the communities did not give children eggs because it was considered taboo. This study majority of the breast fed children attained minimum meal frequency unlike their counterparts, the non- breastfed children. This finding was in agreement with that of a study conducted in Kibera, Nairobi [23]. Frequent meals are required to ensure the child receives enough energy [12]. In this study, over half of the mother s knew that children should be fed based on hunger cues which could be one of the influences on their feeding frequencies since some children may not necessarily show hunger cues.

In this study, majority of the breastfed children attained minimum meal frequency, a lower percentage attained the minimum dietary diversity and consequently, a lower percentage attained the minimum acceptable diet. This is comparable to the findings in Korogocho slum [15] and in Kibera slum Nairobi [24], where many children attained minimum meal frequency but did not attain minimum dietary diversity. Minimum acceptable diet is considered adequate if a child consumes varied diets and at the recommended meal frequencies.

Stunting rates of this study were lower than the national figures in children under five years. This was possibly because the study considered children aged 6-23 months old and also the fact the stunting rates increases with child age. Wasting was higher than the national figure. Underweight compared well with the national figure but was double the prevalence of underweight children in Nairobi province. However, underweight was similar to underweight rates in Central province as reported in KDHS [10]. The malnutrition rates were higher compared to Korogocho slum [15], and Kibera slum [24].

Meeting the minimum dietary diversity, minimum meal frequency and minimum acceptable diet is associated with better nutritional status of children. Several studies have shown a positive relationship between complementary feeding practices and child nutritional status. A recent study in Korogocho slums[15], found that non- attainment of the minimum acceptable diet was a predictor of wasting in children 6-23 months. This study found a relationship between the frequency of feeding and child nutritional status (wasting and underweight).

\subsection{Conclusions}

\section{Conclusion And Recommendation}

This study had limitations like, it was carried out in an urban public health centre and the findings can only be generalized to mothers living in similar circumstances. The sample was recruited from a health centre and not from the households and therefore not be representation of all mothers, some entire mothers in urban areas do not attend public health centers for child welfare clinics especially those from middle and higher socioeconomic classes. These limitations notwithstanding the present study also have strength. Urban areas are heterogenous and so mothers of different tribes and cultural diversity were represented hence giving a true picture of complementary feeding practices and child nutritional status in the country.

Complementary feeding practices were on the whole appropriate; in terms of introduction of solids, semi-solids and soft foods to children 6-8 months and minimum meal frequency especially for the breastfed children. Dietary diversity was low because of the limited socio-economic capability of the respondents to purchase a variety of foods.

\subsection{Recommendations}

This study was done in an urban poor-resource setting among mothers recruited from a health facility and therefore the findings may not be representative of mothers from such a setting. It is therefore recommended that a similar study in a community setting be conducted to verify the findings of this study.

\section{References}

[1]. WHO, (2006a). Infant and Young Child feeding counseling: An Integrated Course Geneva

[2]. WHO, (2005). Guidingprinciples feeding non breastfed children 6-24 months of age Geneva, Switzerland

[3]. Thairu, L. Pelto, G., Levi, and H. E., (2003). Improving feeding practices, current patterns; common constrainsand the design of intervention. Food NutritionBulletin, 24(1): 45-82. 
[4]. Lutter, C. K. and Rivera, J. A. (2003). Nutritional status of infants and young children and characteristics of their diets. Nutrition Journal; 133: 29415-29495.

[5]. WHO, (2003). Global Strategy for Infant and Young Child Feeding. Geneva, Switzerland.

[6]. ACCISCN, 2000).The Fourth Report on World Nutrition Situation. Geneva, Switzerland.

[7]. WHO, (2000).The Global Database on Child Growth and Malnutrition Forecast of Trend WHO, Geneva: Switzerland.

[8]. UNICEF, (2007). Status of Child survival and Development in Eastern and Southern Africa. UNICEF, Kenya.

[9]. Ministry of Public Health and Sanitation (MOPHS). National Strategy on Infant and Young Child Feeding strategy 2007-2010. Ministry of Public Health and Sanitation. Nairobi: Kenya.

[10]. KNBS and ICF Macro (2010). Kenya Demographic Survey 2008-2009, Calverton, Maryland: KNBS and ICF Macro.

[11]. WHO, (2007). Indicators for assessing infant and young child feeding practices, part 1 definitions. Conclusions of a consensus meeting held on 6-8, November, 2007 in Washington D.C., USA.

[12]. PAHO/WHO. (2003). Guiding principles for complementary feeding of the breast-fed child. Washington DC, USA.

[13]. WHO, (2006b). Child Growth Standards. Geneva, Switzerland

[14]. Fotso, J. C., Gitau, T. M., Kyobutungi, C., Madise, N. J., Murage, K. E., Mutua, M. K., and Yatich N. (2011). Patterns and determinants of breastfeeding practices and complementary feeding in urban informal settlement. Nairobi, Kenya. BiomedicalCentral Public health, 11: 396.

[15]. Kipruto, K. J. (2013). Complementary feeding and nutritional status of children aged 6-23 months in Korogocho slum, Nairobi County, Kenya. Msc. Thesis Kenyatta University

[16]. Mukuria, G. A., Kothari. M., and Noureddine, A. (2006). Infant and young child feedingUpdate ORC Macro Calverton, Maryland, USA.

[17]. WHO, (2001). Guiding principles of complementary feeding. Geneva, Switzerland.

[18]. Hatloy, A, Hallund, J, M., Oshang, A. (1998). Food variety, socio economic status and nutritional status in urban and rural areas of Koutiala (Mali). Public Health Nutrition, 3(1) 57-65.

[19]. Blomme, G., Ekesa, B. N., and Garming, H. (2011). Dietary diversity and nutritional status of pre-school children from Musadependent households in Gitega (Burundi) and Butembo (Democratic Republic of Congo). African Journal of food, Agriculture, Nutrition and Development, 11: No 4.

[20]. Mbagaya, M. G. (2009). Child feeding practices in rural Western Kenya community. Journal of Primary Health Care, Family Medicine. 1 (1), 15-19.

[21]. Kumudha, A., Avishek, H.,Khan, M. E.(2010). Complementary feeding in rural Utter Pradesh. The Journal of Family Welfare, special issue, 56:1-56.

[22]. Hellen keller international, Nepal. (2010). Breastfeeding and complementary feeding practices are less than adequate among mothers of children 12-23 months in the Baitadi District of Nepal. Nepal nutrition and food security bulletin, 3rd issue

[23]. Adere, J. W. (2006). Feeding practices and nutritional status of children 6-36 months in Muslim and Christian households: A human rights perspective. A case study of Kibera in Nairobi, Kenya. University of Nairobi.

[24]. Kariuki, F. N., Kibui, M. M., Mwirichia, M. A. and Zani, K. K.(2002). Prevalence and risk factors of malnutrition of children 6-23 months in Kibera Nairobi, Kenya. Journal of National Institute of Public Health, 51(1): 45-47 